\title{
Food for the Dogs: Consumption and Wealth Inequality in Bong Joon-Ho's Parasite
}

\author{
Tauri Hagemann, Ball State University
}

This essay analyzes the ways in which food throughout the film Parasite symbolizes the divide between rich and poor, using contemporary research to further build on how food is a signifier of class and wealth. From the less wealthy eating prepackaged foods, to using a fruit allergy as a weapon against someone, there is a clear indication throughout the film of food as a signifier of status and class. I take this divide and analyze its significance to the modern culture and society of South Korea, then further apply this to its relevancy in a modern United States. Parasite flourished in American society-both are countries wherein a capitalist 'meritocracy' rules for the most part, and an analysis of the culture around the film will show the ways in which the cultures that consumed this media are similar in their class divides.
Bong Joon-Ho's Parasite received numerous awards and much critical acclaim at the 2020 Academy Awards, a remarkable feat in general, let alone for a foreign film. The film was also the first non-English production in the Oscar's history to take home the award for Best Picture. Joon-Ho, however, is neither new to the directorial world, nor to the theme of class and division. Unfortunately, because of its recency, having only debuted in cinemas a little over a year ago, Parasite has not yet received much scholarly criticism. However, there is no shortage of critique on class structures in the U.S., as well as in South Korea, and enough film commentary exists to suggest a viable popular opinion regarding the film. The division between classes and the difference in opportunity and accessibility as exemplified through the Kim and Park families is a consi-

stent and prominent theme throughout the film, and thus can easily be intuited to show the ways food studies further complicate this class divide. Utilizing contemporary research and commentary, this essay will analyze the ways in which class divide is represented in the film through the lens of food studies and consumption, including poverty as demonstrated through food insecurity, an ignorance on the part of upper classes, and food used as a physical conduit for violence and aggression.

Parasite was a film that was very well-received internationally, and its many awards and acknowledgements are proof of this. As already noted, it was the first non-English film to receive Best Picture, among several other Academy Awards, as well as being featured and receiving recognition at the Cannes Film Festival in France. The film follows the Kim family, who live in a small basement apartment in Seoul, South Korea. The family is visibly poor, until they are presented with the opportunity to find work with the Park family, who are visibly wealthy. Obtaining these jobs, however, requires lying about their identities and creating false personas more qualified and educated than the Kims really are, as well 
as spreading lies about the others already employed by the Parks to garner mistrust and get them fired to open more opportunities for the Kims. All of these lies and cutthroat tactics to achieve financial prosperity end up catching up to the Kims, and the final arc of the movie results in intense violence and bloodshed. The main theme or premise behind this film is the unbridgeable gap between the poor and the wealthy elite, and this is a notion that people internationally, especially in the United States, understand to an extensive degree. We are told that we live in a meritocracy wherein all one must do to become successful is put in hard work. At the same time, the rich keep getting richer and the poor remain poor, showing that there must be a flaw in this ideology.

The COVID crisis and the quarantine of the last year have been clear contributors to furthering this class divide. Over the course of around three months of shutdown of everything non-essential, many people were unable to work and therefore unable to bring home a paycheck for their families. After some businesses started reopening, many remained closed or were forced to permanently shut down because of financial losses from three months with no business. A CNBC article from mid-October found that at that time over 100,000 small businesses had already been forced to permanently close their doors because of an inability to keep up revenue while complying with new COVID guidelines and regulations (Adamczyk). The government did send out a stimulus check, but many people either did not receive any stimulus or the small amount they received did not compensate for their loss of employment. Now, a year since the United States' official lockdown, the COVID crisis is finally beginning to push through more stimulus aid and work on making vaccinations and treatments more readily accessible.

Not everyone faced these struggles during the quarantine, though; because of in-person retailers and shopping options being closed for so long, many people took to shopping from online sources like Amazon. Over the course of the quarantine and the pandemic, Jeff Bezos, the CEO of Amazon, continued to grow richer and amass a greater net worth. Over a roughly seven-month period, Bezos's wealth growth was over $\$ 90$ billion, bringing his total net worth to over $\$ 200$ billion (Stebbins). In a time where people in our nation were struggling to even put food on the table, Bezos continued growing richer and richer and nearly doubled his net worth. This ties directly into the idea of food security-Bezos and others like him had no worries for their families or their own well-being financially, whereas those 100,000 small businesses that were forced to close have resulted in an even larger number of people now unemployed and afraid if they will even be able to afford to put food on the table for their families with what little income they may have. In an interview with The Atlantic, Joon-Ho discussed this wealth gap internationally, saying, "I think the state of polarization applies not only to Korea but anywhere across the world. [South] Korea has achieved a lot of development, and now it's a fairly wealthy country, but the richer a country gets, the more relative this gap becomes" (Sims). Marcus Noland remarks how "South Korea's development over the last half century has been nothing short of spectacular. . . . [yet] still needs to fix a labor market in which some workers have extensive benefits and job protection and others do not" $^{\prime \prime}(17,20-21)$.

The South Korean education system has also played into this increasing class divide and polarization. In South Korea, as in other countries including the United States, "higher education has been transformed from an elite system to a mass system" (Doo Hwan Kim 436-437). University education is 
no longer something that puts a person a step ahead in the workforce as much as it is something that is expected and seen as necessary to find sustainable work. However, despite this ideal, income and class status in South Korea still heavily impact available opportunities: "They view expansion of higher education as a process of diversion, which reserves higher-status opportunities for the elite by channeling children of the working class to low-status post-secondary opportunities" (Doo Hwan Kim 437). We can also see this phenomenon clearly reflected in Joon-Ho's Parasite. Kim Ki-Woo has a long-time friend named Min who connects him with his job with the Park family in the first place. Min is university educated, and this is what helped him find his position tutoring for the wealthy family-his education has provided him with opportunity. Education brings opportunity, opportunity brings financial stability, and financial stability brings food security_all things of which the Kim family were lacking at the start of the film.

As has been referenced several times throughout this essay, money and food are inherently related in that money is needed to obtain food. This is made very clear in one of the first scenes of the film, wherein we see the poorer Kim family sitting around their small kitchen table eating food that looksand sounds-like it is coming out of plastic packaging. We also see them all with the same canned beverage, though whether it is soda or beer or an alcoholic beverage is unclear (Parasite). They're eating cheap, packaged, processed foods like one would buy from a vending machine because this is what their family is able to afford on the small income they make folding pizza boxes. According to Barbara Briers and Sandra Laporte, "financially dissatisfied people may try to replenish their need for financial resources by consuming caloric resources or food energy because money and food are closely related, exchangeable resources" (767). Briers and Laporte also posit that because of this increased value assigned to food energy, those who are financially dissatisfied also tend to consume food in larger quantities and higher caloric contents. Going from the vending machine assumption, this would make perfect sense of the Kim family. Prepackaged snacks and beverages tend to be high in calories and cheap to acquire, while also being alarmingly lacking in nutrient or vitamin contents. Another study also found that the amount of people who are financially dissatisfied, particularly in developing Asia, is startlingly large: "Around 560 million people lived in slums in Asia and the Pacific in 2014, which corresponds to about 30 percent of the population." While the percentage has fallen year to year, "the absolute number has risen ... due to overall population growth" (Aizawa 28). Looking at the Kim's basement apartment and the small table they crowd around in their center room to eat, it is not too out of bounds to assume that they would fall into this category of financially dissatisfied people.

This wealth divide becomes more apparent once the Kim family becomes employed by the Parks. The Parks are a family that live a life drastically different from the Kims-they employ several personal assistants and tutors, they live in a sizable house with a lavish and manicured lawn, and they can do so off of the patriarch's salary with the mother and children of the house not having to work at all. One scene that is particularly striking in showing this wealth divide is when the Park family decides to go on a camping trip for their son's birthday and leave Kim Chung-sook, their caretaker and the mother of the Kim family, to stay in the house and look after their dogs. The matriarch of the Park family goes into extensive detail on each of the dog's diets, explaining how one of them eats differently from the others and has food that is made from crab legs (Parasite). She seems completely oblivious to the extent of luxury and comfort this exemplifies in her family, ignorant and unappreciative of just how prosperous they 
really are. For the Kims, who can only afford to get themselves a pizza after several of them have been working for the Parks for a few weeks, seeing dogs who eat fancier ingredients than them is very unsettling. This dichotomy is especially seen after the Parks have left and the Kim family have made themselves comfortable, taking advantage of a space and a prosperity that at any other time is unavailable to them. While the Parks are aware that Chung-sook is in the house, they are unaware that any of their other employees are related and therefore do not know that the family is all present in their absence. While the Kims are lounging around the house enjoying the Parks' food and drink, daughter Ki-Jung inspects this package of dog food and scoffs upon seeing what it is composed of. One scholar argues that this idea of "upward comparison to those with more income generally leads people to feel they need more to be satisfied" and how this "perceived need has a precise relationship to risk taking" (Payne 4643). Comparing what the Parks have to their own resources, the Kims develop a feeling that they need more to be happy, which causes them to take greater risks in order to achieve this wealth and satisfaction. They feel a sense of injustice at the wealth gap they are experiencing firsthand and decide to take matters into their own hands to level this gap as much as possible.

What serves to make matters even worse for the Kims is that the Parks, who have the wealth and prosperity to eat basically whatever they want, also seem to have a strange affinity for cheap and easy food. When a storm starts and the Park camping trip eventually turns into a bust, the mother of the family calls Kim Chung-Sook on their way home and asks her to prepare their son, Da-Song, his favorite meal for when they return. This favorite meal? Ramdon, a combination of packaged ramen and udon noodles (Parasite). For a family that is so well off, it comes as somewhat strange that Da-Song's absolute favorite food is comprised of pre-packaged noodles that are affordable even to poorer families like the Kims. It is not only Da-Song who enjoys the cheap and easy meal, though-when the Park family returns home, Da-Song is upset and angry and retreats to his room without eating. The family matriarch offers the food to her husband but, upon his declination, eats the Ramdon instead. Not only does she eat it, she eats quickly, signifying either an intense hunger, a deep love for the dish, or a combination of both (Parasite). It's not just their young son who enjoys cheap food-it's the adults in the house as well who supposedly have an appreciation for the 'finer things in life' that would exclude something this simple. This serves to emphasize a very important point in the film: while the Parks have the means to obtain practically anything, they are not necessarily appreciative of this fact. This is the same idea emphasized through the image of the crab leg dog food; the family is completely oblivious to their own wealth and prosperity and therefore do not appropriately acknowledge their privilege. The Kim family, on the other hand, knows that they are not at all considered wealthy, but, in contrast to the Parks, they are willing to do nearly anything to find a way to obtain the means to that wealth and prosperity, even if it takes lying about their lives and identities to do so.

Another very interesting yet less obvious way in which food comes to play a role in the significance of class divide in Parasite is through smell and connotation. When the Park family returns home from their failed camping trip, the Kims have not yet had time or opportunity to leave without being seen, and as such end up hiding under the table in the main living room area. While here, the Parks can be overheard talking, and at one point the patriarch of the household can be heard saying that Kim KiTaek, the Kim father who at this point works as the Parks's chauffeur, smells badly-specifically, he says 
that he smells like radishes (Parasite). This is a comment that strikes Ki-Taek much more deeply than one would anticipate and plays a very large role in the climactic final events of the film.

While the Parks are out the old housekeeper returns, and conflict ensues between the old and new help of the Park family. The old housekeeper had been working in that house since the previous owner, and it is revealed that she had been hiding her husband in a nuclear cellar underneath the house that the Parks were unaware of, allowing him to live there for free and providing him with food. When he was much younger, Park son Da-song saw this man coming up the stairs late at night and was so frightened that he had a seizure. In the climax of the film, more conflict embroils between the Parks and the old help, all hidden underneath the Parks's elaborate picnic party for Da-song. Eventually, this man leaves the basement and grabs a knife as he passes on his way to the yard, where he attacks the Kim family and gravely injures the daughter Ki-jung in front of a crowd of people. Upon seeing this terror from his past resurface, Park son Da-Song has another seizure and needs to be taken to the hospital. His father yells for Kim Ki-Taek to get the car ready and go, not knowing that the body Ki-taek is cradling is that of his daughter. Instead, he throws the keys towards the Parks, and they land in the grass and end up under the body of the previous housekeeper's husband who has been physically struggling with the mother Kim Chung-sook most of this time. When Mr. Park goes to retrieve the keys, he recoils for a moment and holds his nose before grabbing them. This is the action that ultimately makes Ki-Taek snap as he rises, grabs the knife previously used to hurt his daughter, and drives it into the chest of Mr. Park. Ki-taek's daughter is about to die, bleeding out on the grass in his arms, and Mr. Park has the audacity to think his bodily odor lingering on the car keys is repulsive enough to take pause in acting to help his own son. There are several places where food makes itself present in the carnage of this final scene-the smell of radishes lingering on these car keys, Mrs. Kim taking down the man who killed her daughter by stabbing him with a sausage skewer, and the whole scene centering around Da-song's birthday and beginning while Kim Ki-jung was bringing out his birthday cake. This is perhaps the most extreme, and yet the most clear and significant, example throughout the film of this disparity between the families and the gap between their lives that they will simply never be able to bridge.

There is also another very direct tie between food and violence in this film, specifically with peaches. The Park's old housekeeper, who gets fired and replaced by Chung-Sook, has an intense and dangerous allergy to peaches. The children in the house enjoy the fruit, but never have it because of their housekeeper's allergy. When trying to get rid of the housekeeper, the Kim children who are employed in the house already use this allergy to their advantage and spread the fibers off the skin of peaches in the air around her, making her cough and react aggressively. Upon these reactions happening increasingly frequently, the housekeeper goes to see a doctor and is spotted there by Kim Ki-Taek, who takes a selfie with her in the background and later expresses concerns to Mrs. Park, saying he overheard the housekeeper talking about tuberculosis. This is ultimately what ends up getting the housekeeper fired-a fabricated sense of secrecy surrounding her health and a perceived endangerment of the Park family. Later, when she comes back for her husband while the Parks are away and the Kims are relaxing around the house, the peach becomes used as a more literal weapon against her, shoved in her face and rubbed against her skin to cause a reaction. In Bong Joon-Ho's words, "Peaches are so pretty to look at, but you can attack someone with them" (Murray). Beyond just the physical representation of the food, 
this further exemplifies how food and consumption are used throughout the film as signs of aggression and class divide. The Kims use the peaches as a weapon against the housekeeper to secure their jobs with the Parks and obtain a better financial standing, thus pushing the poor housekeeper down into unemployment

and poverty.

Through these given examples, food and consumption clearly play a major role in the way that class and social status are portrayed throughout Parasite, being so vital as to be the conduit for the final moments of violence and bloodshed within the film. One's means of obtaining food and for consumption are inherently tied to their social and financial standing, and this is clear to see in the divide between the food and consumption habits of the Parks and the Kims. This is not just an issue that exists within the screen either-wealth gaps in South Korea as well as the United States are an ever-present issue as the rich grow richer and the poor stay poor, and this film is an exemplary demonstration of the destructive nature of this social structure. While Parasite is unarguably a dramatized representation of the consequences of this divide, it brings about some very important points and one essential question for us to consider: Who is really the parasite of the film? Is it the rich who rely on the services of the poor to thrive without being appreciative of these services or the privilege that they themselves have? Or is it the poor who sap money and resources from the rich in hopes of financial ascension? 
Works Cited

Adamczyk, Alicia. 7 Months into the Pandemic, Small Business Owners Don't Know How Much Longer They Can Hold on: 'We Are in Survival Mode.' 15 Oct. 2020, www.cnbc.com/2020/10/15/small-businesses-are-in-survival-mode-as-the-covid-pandemicdrags-on.html.

Aizawa, Toshiaki, et al. "Housing Inequality in Developing Asia and the United States: Will Common Problems Mean Common Solutions?" Cityscape, vol. 22, no. 2, 2020, pp. 23-60.

Briers, Barbara, and Sandra Laporte. "A Wallet Full of Calories: The Effect of Financial Dissatisfaction on the Desire for Food Energy." Journal of Marketing Research, vol. 50, no. 6, 2013, pp. $767-781$.

Doo Hwan Kim, and Yool Choi. "The Irony of the Unchecked Growth of Higher Education in South Korea: Crystallization of Class Cleavages and Intensifying Status Competition." Development and Society, vol. 44, no. 3, 2015, pp. 435-463.

Murray, Iana. "How Peaches Went From Sexual Innuendo to Symbol of Doom on Screen." Them., Them., 5 Oct. 2020, www.them.us/story/peach-danger-call-me-by-your-nameratched-parasite.

Noland, Marcus. "South Korea: The Backwater That Boomed." Foreign Affairs, vol. 93, no. 1, 2014, pp. 17-22.

Parasite. Directed by Bong Joon-Ho, CJ Entertainment, 2019.

Payne, B. Keith, et al. "Economic Inequality Increases Risk Taking." Proceedings of the National Academy of Sciences of the United States of America, vol. 114, no. 18, 2017, pp. 4643-4648.

Sims, David. "How Bong Joon Ho Invented the Weird World of 'Parasite.'" The Atlantic, Atlantic Media Company, 10 Feb. 2020, www.theatlantic.com/entertainment/archive/2019/10/ bong-joon-ho-parasite-interview/600007/.

Stebbins, Samuel, and Grant Suneson. "Jeff Bezos, Elon Musk among US Billionaires Getting Richer during Coronavirus Pandemic." USA Today, Gannett Satellite Information Network, 1 Dec. 2020, www.usatoday.com/story/money/2020/12/01/american-billionaires-thatgot-richer-during-covid/43205617/. 